\title{
Intrauterine balloon tamponade in the management of severe postpartum hemorrhage: A case series from a busy UK district general hospital
}

\author{
Sahithi Tirumuru, Samiramis Saba, Hassan Morsi*, Basem Muammar \\ Department of Obstetrics and Gynaecology, Russells Hall Hospital, Dudley Hospitals NHS Foundation Trust, Dudley, UK \\ Email: *hassan.morsi@dgh.nhs.uk
}

Received 24 October 2012; revised 22 November 2012; accepted 4 December 2012

\begin{abstract}
Objective: To evaluate the effectiveness of balloon tamponade in the management of postpartum hemorrhage (PPH). Methods: Retrospective review of 58 women who underwent balloon tamponade for severe PPH, during a period of 5 years and 10 months, at Russells Hall Hospital, a busy district general hospital in UK. Clinical success was defined as control of bleeding without need for further intervention. Results: Fifty-eight women (mean age, 30 years; range, 18 - 42) underwent balloon tamponade, of which twenty seven (46.5\%) women delivered vaginally and 31 (53.5\%) women were delivered by cesarean section. Uterine atony was the main cause of PPH (31 cases). Balloon tamponade was used prophylactically in $\mathbf{1 1}$ high risk women in anticipation of potential PPH. Rusch balloon was used in 48 cases and Bakri balloon in 10 cases. Clinical success rate of balloon tamponade was $87.2 \%$. Three patients in this study required hysterectomy. Conclusion: Balloon tamponade is an effective means of controlling severe PPH with success rates of around $87 \%$. There should also be a low threshold for prophylactic use of balloon tamponade in women at high risk of PPH, considering its ease of use, low complication rate and ability to maintain reproductive ability.
\end{abstract}

Keywords: Balloon Tamponade; Effectiveness;

Postpartum Hemorrhage

\section{INTRODUCTION}

Worldwide, obstetric hemorrhage remains a significant problem and is responsible for 127,000 deaths annually. Postpartum hemorrhage (PPH) is the most common type of obstetric hemorrhage and accounts for the majority of the 14 million cases annually [1].

In the UK, deaths from obstetric hemorrhage are rare

"Corresponding author.
(0.8:100,000 births) [2]. According to the 2009 Scottish Confidential Audit of Severe Maternal Morbidity, major obstetric hemorrhage is the most common cause of severe maternal morbidity affecting $78 \%$ women with severe morbidity, giving a rate of 5.18 per 1000 live births in Scotland [3]. Hysterectomy is the ultimate measure to control bleeding and avoid maternal death. The rate of peri-partum hysterectomy, as reported by the UK Obstetric Surveillance System (UKOSS), is 0.41:1000 births [4].

Recently Uterine balloon tamponade in the management of PPH has been reported increasingly with success rates of over $84 \%$ [5]. A systematic review of conservative PPH management concluded that, it should be considered as a first step in the management of intractable $\mathrm{PPH}$, which is not due to genital trauma or retained tissue and which does not respond to uterotonics [5].

The purpose of this study is to evaluate the effectiveness of balloon tamponade in PPH management and to report our experience of its use in a busy district general hospital (5300 deliveries annually).

\section{MATERIALS AND METHODS}

This is a retrospective case series of 58 patients who underwent balloon insertion to control PPH at Russells Hall Hospital, Dudley in England between March 2006 to December 2011. Obstetric theatre registers were surveyed to identify patients and case records were retrieved. Data analysed included age, parity, onset of labor, mode of delivery, estimated blood loss, blood transfusion and outcomes including need for additional surgery and complications. Investigational review board approval was not requested for this anonymous, retrospective, data abstraction and analysis study.

We defined PPH as $>500 \mathrm{ml}$ estimated blood loss after vaginal delivery or $>1000 \mathrm{ml}$ after cesarean section (CS) [6]. Uterine and cervical trauma, deficient coagulation or retained placental tissue had already been excluded as causes of PPH. Initial management of atonic PPH in- 
cluded resuscitative measures, hypovolemia correction, uterotonics, uterine massage and/or bimanual compression. In the majority of cases the decision for balloon insertion was made on the basis of active continuous hemorrhage despite conservative measures. In some high-risk women balloon insertion was carried out as a prophylactic measure in anticipation of potential PPH.

All balloon catheters were inserted in the operating theatre under regional or general anesthesia. When balloon insertion was contemplated, either Rusch balloon (Rusch UK, Teleflex, Old Amersham, UK) or Bakri balloon (Bakri SOS balloon; Cook Woman's Health, Spencer, IN) was used, depending on the surgeon's choice.

The insertion of the balloon was performed transvaginally if PPH followed vaginal delivery (using sponge holding forceps or manually into uterine cavity using ring forceps to hold the cervix). If introduced during a CS, the catheter was either inserted through the uterine incision (pushing the tip to the fundus and the distal end of the balloon shaft through the cervix with an assistant pulling vaginally) or transvaginally and inflated after the uterus was closed.

After insertion, the balloon was inflated with normal saline until resistance was felt or bleeding was controlled. In cases of atonic PPH, oxytocin infusion $(40 \mathrm{U} / 36 \mathrm{~mL}$ normal saline) was continued for a minimum of 4 hours to keep the uterus well contracted over the balloon. Urinary catheter was left in situ for the duration of balloon tamponade in all cases. Following balloon insertion, all the patients were closely monitored in the high dependency unit.

Clinical success was defined as control of bleeding following balloon insertion without further intervention.

\section{RESULTS}

In total, 63 women underwent balloon tamponade for PPH management during the study period. Notes were available for 58 women, who were the subject of the present study. Mean age of the patients was 30 years (range 18 - 42 years). The gestational age was between 34 to 42 weeks. Thirty women (51.7\%) were nulliparous, and 28 (48.2\%) were multiparous. Twenty seven women (46.5\%) delivered vaginally and of these, 20 (74\%) had a normal vaginal delivery and 7 (26\%) had an instrumental delivery. Out of the 27 women who delivered vaginally, labor was either induced or augmented with oxytocin in $55.5 \%$ women (15/27). Thirty one (53.5\%) patients were delivered by CS, of which 12 (38.7\%) were emergencies. PPH was primary in all patients.

In 47 cases balloon insertion was therapeutic to control intractable hemorrhage. The primary cause of PPH in this group was atony, which accounted for 31 cases. Other causes included retained products (5 cases), pla- centa previa (4 cases), vaginal lacerations (3), placental bed bleeding due to clinically suspected morbid placental adherence (2) cervical tear (1) and missed uterine angle at CS (1). In cases where retained products was the main cause of PPH, exploration of the uterus and removal of retained products of conception was carried out prior to balloon insertion. In case of three women with vaginal lacerations and one woman with cervical tear, balloon tamponade was attempted to control intractable bleeding from the lacerations despite suturing.

Balloon insertion was carried out as a prophylactic measure in 11 women in anticipation of potential PPH. All these women had identifiable risk factors for PPH. This included 7 women with placenta previa, 2 women with atonic uterus (where bleeding settled following uterotonics but the surgeon nevertheless decided to insert the balloon prophylactically as the uterus still felt atonic), 1 woman with a $6 \mathrm{~cm}$ anterior uterine wall fibroid and 1 woman who had placental abruption. All cases of prophylactic balloon insertion except one, were performed at caesarean section.

All patients had active management of the third stage of labor with a bolus of Syntocinon (oxytocin 5 units IV or 10 units IM) or Syntometrine IM (ergometrine maleate 500 micrograms, oxytocin 5 units/mL). Fifty seven patients received oxytocin infusion (40 units in $36 \mathrm{ml} 0.9 \%$ saline at a rate of $10 \mathrm{ml} /$ hour), a total of 16 patients (27.5\%) had ergometrine IM or IV; 27 (46.5\%) were given carboprost IM; and misoprostol (0.8 - $1 \mathrm{mg}$ rectally) was given to 28 patients (48.2\%).

Forty-four women underwent the procedure under regional anesthesia, whereas 14 had general anesthesia.

Placement of balloon was intrauterine in 55 patients. Balloon was placed in the vagina to stop the bleeding from vaginal lacerations in 2 patients. Balloon tamponade was performed with 2 separate balloons in 1 patient. The superior balloon was placed in the uterus to control bleeding due to uterine atony, while the inferior balloon was placed in the vagina to control bleeding from vaginal lacerations.

Rusch balloon was used in 48 cases and Bakri balloon was used in 10 cases. The amount of saline instilled to inflate the balloon ranged widely from 80 to $1300 \mathrm{ml}$ (mean $408 \mathrm{ml}$ ) depending on the size and capacity of the uterus and according to the perception of resistance on inflation and amount of insufflation required to achieve haemostasis. For the Rusch, the average was $423 \mathrm{~mL}$. For the Bakri, the average was $360 \mathrm{~mL}$. Twenty-one (36.2\%) women had vaginal packing following balloon insertion to help retain the balloon in place.

The balloon was inflated for an average of 29 hours before removal (range $6 \mathrm{~h}$ to $80 \mathrm{~h}$ ). The balloon was removed within 8 hours in one patient, within 8 - 24 hours in 10 patients and within $24-48 \mathrm{~h}$ in 40 patients and 
balloon was left in for more than 72 hours in one patient. Removal of the balloon was a one step procedure in 38 (73\%) women and deflation was a two-stage procedure in 14 (27\%) women. Balloon deflation was done only in the day time, under very close observation and where deflation time happened to be during late hours, it was deferred to the following morning for safety considerations.

Total estimated blood loss was between $500 \mathrm{~mL}$ to $4000 \mathrm{~mL}$ (mean, $1572 \mathrm{~mL}$ ). Twenty-three patients (39.6\%) received blood transfusions (range, 1 to 13 units of packed red blood cells with a mean of 4 units per patient).

There were no cases of re-bleeding after balloon removal.

Broad-spectrum antibiotics were systematically used just before the operation in 12/58 (20.6\%) of cases and prophylactic antibiotics were used for the duration of balloon tamponade or 5 - 7 days based on the operators' decision in 31/58 (53.4\%) cases. In 15 (26\%) cases, the procedure was carried out without antibiotic cover. All the patients who underwent laparotomy received antibiotics.
In the therapeutic group, balloon tamponade was successful in stopping PPH without further intervention in $41 / 47$ cases, with a success rate of $87.2 \%$. Out of the six patients who required further intervention (Clinical details Table 1), 1 patient was managed conservatively with two carboprost doses, the second returned to theatre for balloon reinsertion as the first balloon was expelled two hours later (due to inadequate insufflation) and the third required a re-laparotomy which revealed hemorrhage from a missed right angle of the CS incision. Three patients required hysterectomy. The first two needed hysterectomy as the balloon failed to stop the PPH. The third patient had an atonic PPH following emergency CS after failed trial of forceps. B-lynch suture (to help the uterine wall provide counter pressure around the balloon) plus cervical cerclage (to help retain balloon in the uterus) were used in addition to intrauterine Rusch balloon to control PPH. This controlled the bleeding and immediate postnatal period was uncomplicated. The patient was discharged home on the fifth post-operative day. She represented with massive secondary PPH 18 days post de-

Table 1. GA, gestational age; PPH, postpartum hemorrhage; EBL, estimated blood loss; SVD, spontaneous vaginal delivery; Em. LSCS, emergency lower segment caesarean section; El. LSCS, elective lower segment caesarean section; ITU, intensive therapy unit; FFP, fresh frozen plasma; STAH, subtotal abdominal hysterectomy; U, units.

\begin{tabular}{|c|c|c|c|c|c|c|c|c|c|}
\hline No. & $\begin{array}{c}\text { Age } \\
\text { (years) }\end{array}$ & Parity & GA & $\begin{array}{l}\text { Mode of } \\
\text { delivery }\end{array}$ & Cause of PPH & $\begin{array}{c}\text { Type of } \\
\text { balloon and } \\
\text { volume }\end{array}$ & $\begin{array}{c}\mathrm{EBL} \\
\text { (liters) }\end{array}$ & Transfusion & Further intervention/final outcome \\
\hline 1 & 23 & P1 & $39+4$ & SVD & Uterine atony & $\begin{array}{l}\text { Rusch } \\
650 \mathrm{ml}\end{array}$ & $3 \mathrm{~L}$ & Blood $4 \mathrm{U}$ & $\begin{array}{l}\text { Balloon fell out after } 3 \text { hours followed } \\
\text { by brisk vaginal bleeding, which was } \\
\text { controlled with } 2 \text { doses of carboprost } 15 \\
\text { minutes apart. }\end{array}$ \\
\hline 2 & 21 & $\mathrm{P0}$ & $42+0$ & Ventouse & Uterine atony & $\begin{array}{c}\text { Rusch } \\
\text { 1st: } 350 \mathrm{ml} \\
\text { 2nd: } 1300 \\
\mathrm{ml}\end{array}$ & $2.5 \mathrm{~L}$ & Blood $5 \mathrm{U}$ & $\begin{array}{l}\text { First balloon fell out after } 2 \text { hours. } \\
\text { Returned to theatre as continued to bleed } \\
\text { and 2nd balloon inserted which controlled } \\
\text { the bleeding. ITU admission due to } \\
\text { massive PPH and anaphylactic reaction } \\
\text { to Penicillin. }\end{array}$ \\
\hline 3 & 19 & $\begin{array}{c}\text { P1 } \\
\text { (prev. C/S) }\end{array}$ & $36+5$ & $\begin{array}{l}\text { Em. } \\
\text { LSCS }\end{array}$ & $\begin{array}{l}\text { Missed hemorrhage } \\
\text { from uterine } \\
\text { incision near } \\
\text { right angle }\end{array}$ & $\begin{array}{l}\text { Rusch } \\
450 \mathrm{ml}\end{array}$ & $3 \mathrm{~L}$ & $\begin{array}{l}\text { Blood } 8 \mathrm{U} \\
\text { Cryoprecipitate } 2 \mathrm{U} \\
\text { FFP } 4 \mathrm{U}\end{array}$ & $\begin{array}{l}\text { Continued to bleed following Rusch } \\
\text { balloon. Second exploratory laparotomy } \\
\text { identified missed hemorrhage from uterine } \\
\text { incision near the right angle. }\end{array}$ \\
\hline 4 & 41 & $\mathrm{P} 0$ & $40+0$ & $\begin{array}{l}\text { Em. } \\
\text { LSCS }\end{array}$ & Uterine atony & $\begin{array}{l}\text { Rusch } \\
1200 \mathrm{ml}\end{array}$ & $4 \mathrm{~L}$ & $\begin{array}{l}\text { Blood } 8 \mathrm{U} \\
\text { Cryoprecipitate } 2 \mathrm{U} \\
\text { FFP } 9 \mathrm{U}\end{array}$ & $\begin{array}{l}\text { Hysterectomy as balloon failed to control } \\
\text { the bleeding. }\end{array}$ \\
\hline 5 & 34 & $\mathrm{P} 0$ & $38+0$ & $\begin{array}{l}\text { El. } \\
\text { LSCS } \\
\text { for twins }\end{array}$ & $\begin{array}{l}\text { Uterine atony and } \\
\text { placental bed } \\
\text { bleeding }\end{array}$ & $\begin{array}{l}\text { Rusch } \\
1000 \mathrm{ml}\end{array}$ & $2.6 \mathrm{~L}$ & Blood $4 \mathrm{U}$ & $\begin{array}{l}\text { Bleeding controlled initially following } \\
\text { balloon. Emergency hysterectomy } \\
\text { preformed } 2 \text { hours later as patient started } \\
\text { to bleed heavily and became unstable. } \\
\text { ITU admission postop. }\end{array}$ \\
\hline 6 & 29 & $\mathrm{P} 0$ & $40+0$ & $\begin{array}{c}\text { Em } \\
\text { LSCS }\end{array}$ & Uterine atony & $\begin{array}{l}\text { Rusch } \\
150 \mathrm{ml} \\
\text { B-lynch } \\
\text { cervical } \\
\text { suture }\end{array}$ & $4 \mathrm{~L}$ & $\begin{array}{c}\text { Blood } 13 \mathrm{U} \\
\text { Cryoprecipitate } 1 \mathrm{U} \\
\text { FFP } 8 \mathrm{U} \\
\text { Platelets } 2 \mathrm{U}\end{array}$ & $\begin{array}{l}\text { Bleeding controlled following balloon and } \\
\text { B-lynch. Discharged home on 5th post-op } \\
\text { day. Returned with massive PPH due to } \\
\text { necrosis on 18th postop day resulting in } \\
\text { emergency STAH. }\end{array}$ \\
\hline
\end{tabular}


livery due to uterine infarction/necrosis, requiring an emergency subtotal hysterectomy.

In terms of complications, two patients in this case series developed postpartum pyrexia due to endomyometritis despite receiving antibiotics and both had exploration of the uterus and removal of retained placental tissue prior to balloon insertion, which is possibly the predisposing factor for developing infection. In one patient (case 6, Table 1) who had B-lynch suture, cervical cerclage and balloon tamponade, massive secondary PPH developed 18 days later necessitating emergency hysterectomy.

In terms of subsequent pregnancies, 3 patients in this series had a subsequent pregnancy following intrauterine balloon. The first patient had a spontaneous vaginal delivery at $37+4$ weeks and the second patient had an elective CS (for previous CS and cervical tear) at 39 weeks. The third patient was an insulin dependent diabetic and had an uncomplicated emergency CS at $34+6$ weeks for sub-optimal CTG.

\section{DISCUSSION}

Surgical options for major PPH include uterine compression sutures, vessel ligation and hysterectomy. These procedures are invasive, involve laparotomy, require specialist expertise, may be associated with significant morbidity and may compromise future fertility. Interventional radiology offers a minimally invasive, fertileity-preserving alternative but requires special equipment, trained interventional radiologists and is not readily available in most obstetric units.

Recently, balloon tamponade has been widely used in the management of PPH unresponsive to standard management. It is likely that, in the UK, a number of women with PPH are successfully managed with uterotonics and intrauterine tamponade alone. According to the UKOSS study, 25\% of women had intrauterine tamponade before the use of another second-line therapy [7].

One of the earliest methods of achieving a tamponade effect to control PPH was by uterine packing [8]. In modern obstetrics, uterine packing has been replaced by balloon catheters due to the risk of uterine injury from blind insertion, infection and concealed hemorrhage. Balloon tamponade is a simple procedure which is readily available in most units and can be easily performed by residents under supervision and has the advantages of immediate results, low cost and less morbidity.

Goldrath (1983) first described the successful use of a Foley catheter to tamponade acute profuse uterine bleeding in 17 of 20 patients [9]. The intrauterine balloon is considered to act by exerting "inward-to-outward pressure" that is greater than the systemic arterial pressure to prevent continual bleeding [10]. Various devices have been used for uterine tamponade such as the SengstakenBlakemore tube, Bakri balloon, Rusch balloon, Foley catheter and the condom catheter balloon. Rusch balloon has the advantages of a larger capacity (a maximum of $1500 \mathrm{~mL}$ ) [11] and low cost. Bakri balloon has a capacity of $500 \mathrm{~mL}$ and is made of silicon instead of latex. An added advantage is that it has a drainage channel to allow blood drainage from the uterine cavity.

A review of case reports, retrospective and prospective studies of balloon tamponade in the management of PPH by Georgiou (2009) showed that success was obtained in 97/106 (91.5\%) cases [8]. The Scottish Confidential Audit of Severe Maternal Morbidity (2009) identified 57 cases where balloon tamponade was used for the management of major PPH; hysterectomy was averted in 50 (88\%) women [3].

Our results show a success rate of similar order. The population studied could be representative of the general population as our hospital is a district general hospital. Balloon tamponade was effective in 41 of 47 cases (87.2\%) of PPH from different causes such as uterine atony, placenta previa, and placental bed bleeding without further intervention. It was effective in avoiding hysterectomy in $93.6 \%$ women. Balloon tamponade was successful in 3 women with intractable bleeding from vaginal lacerations despite suturing. The use of balloon tamponade to treat PPH due to vaginal lacerations has been described by Tattersall (2007) [12]. Our study has also shown that balloon tamponade can be successfully used as a prophylactic method in women at high risk of PPH such as placenta previa, uterine atony and in 1 patient with a $6 \mathrm{~cm}$ fibroid.

In our study, the balloon was inflated for an average of 29 hours before removal. Studies by G. S. Condous et al. and J. Seror et al. quote similar results and duration of balloon tamponade in their studies was an average of 26 hr, 14 minutes and $30 \mathrm{hr}$ respectively [13,14]. In our study, only $36 \%$ women had vaginal packing following balloon insertion and vaginal pack may only be necessary in cases of PPH involving a dilated cervix [8].

There were 2 cases of endomyometritis and both patients had manual exploration of uterus for retained products as a predisposing factor for endomyometritis. In 1 patient who had B-lynch, balloon tamponade and cervical cerclage, though the combined procedure was successful in controlling the bleeding in the immediate postnatal period, the patient developed massive secondary PPH due to necrosis resulting in subtotal hysterectomy 18 days later. Uterine necrosis has been reported following B-Lynch suture alone [15] and following combined uterine compression suture with intrauterine balloon tamponade [16]. Uterine necrosis in this case could be attributed to poor perfusion following B-lynch or combined method, rather than due to balloon tamponade it- 
self. Other potential complications of the combined method include endomyometritis and uterine lacerations. To minimize the risks with the combined method, Diemert, et al. suggested inflating the balloon completely only after placement of the sutures while visualizing the myometrial response and minimizing duration of the maximum balloon pressure by deflating it by $50 \%$ after 12 hours [17].

The limitations of our study include its retrospective methodology and the lack of a control group. Another limitation is the estimation of total blood loss and use of balloon catheters was at the discretion of the attending physician. In our study only $53.4 \%$ of patients were given antibiotics for the duration of balloon tamponade and $26 \%$ of patients did not receive any antibiotics. We addressed this shortcoming by updating our guideline to include antibiotic prophylaxis for the duration of balloon tamponade and disseminating this information to all staff. Furthermore, it is impossible to predict the outcome in the prophylactic balloon tamponade group if the balloon had not been used. The authors however feel that the identifiable risk factors for PPH justified the clinical decision to use the balloon prophylactically in those patients. Studies have described the prophylactic use of the balloon tamponade to avert PPH [18,19].

In conclusion our large, single centre series confirms that balloon tamponade is an effective means of controlling severe PPH with success rates of approximately $87 \%$. There should also be a low threshold for prophylactic balloon tamponade use in women at high risk of $\mathrm{PPH}$, considering its ease of use, low complication rate and ability to retain fertility. This treatment is also cost effective as it may avoid the need for hysterectomy and also hospital stay and convalescence are likely to be shorter compared to other invasive surgical procedures. Future prospective studies are warranted to determine the ideal fluid volume for balloon inflation, tamponade duration and duration of oxytocin infusion.

\section{REFERENCES}

[1] World Health Organization (2007) Making pregnancy safer. Reducing the global burden: Postpartum hemorrhage.

http://www.who.int/maternal_child_adolescent/document s/newsletter/mps_newsletter_issue4.pdf

[2] Lewis, G. (2007) The Confidential Enquiry into Maternal and Child Health (CEMACH). Saving mothers' lives: Reviewing maternal deaths to make motherhood safer2003-2005. The Seventh Report on Confidential Enquiries into Maternal Deaths in the United Kingdom, CEMACH, London.

[3] NHS Quality Improvement Scotland (2010) Scottish confidential audit of severe maternal morbidity 2009. 7th Annual Report, NHS Quality Improvement Scotland,
Edinburgh.

[4] Knight, M., Kurinczuk, J., Spark, P. and Brocklehurst, P. (2008) Cesarean delivery and peripartum hysterectomy. Obstetrics and Gynecology, 111, 97-105. doi:10.1097/01.AOG.0000296658.83240.6d

[5] Doumouchtsis, S.K., Papageorghiou, A.T. and Arulkumaran, S. (2007) Systematic review of conservative management of postpartum hemorrhage: What to do when medical treatment fails. Obstetrical and Gynecological Survey, 62, 540-547.

doi:10.1097/01.ogx.0000271137.81361.93

[6] Baskett, T.F. (1999) Complications of the third stage of labour. In: Essential Management of Obstetrical Emergencies. 3rd Edition, Clinical Press, Bristol, 196-201

[7] Kayem, G., Kurinczuk, J.J., Alfirevic, Z., Spark, P., Brocklehurst, P. and Knight, M. (2011) Specific secondline therapies for postpartum haemorrhage: A national cohort study. British Journal of Obstetrics and Gynaecology, 118, 856-864. doi:10.1111/j.1471-0528.2011.02921.x

[8] Georgiou, C. (2009) Balloon tamponade in the management of postpartum haemorrhage: A review. British Journal of Obstetrics and Gynaecology, 116, 748-757. doi:10.1111/j.1471-0528.2009.02113.x

[9] Goldrath, M.H. (1983) Uterine tamponade for the control of acute uterine bleeding. American Journal of Obstetrics and Gynecology, 147, 869-872.

[10] Ishii, T., Sawada, K., Koyama, S., Isobe, A., Wakabayashi, A., Takiuchi, T., et al. (2012) Balloon tamponade during cesarean section is useful for severe post-partum hemorrhage due to placenta previa. Journal of Obstetrics and Gynecology Research, 38, 02-07

[11] Keriakos, R. and Mukhopadhyay, A. (2006) The use of the Rusch balloon for management of severe postpartum haemorrhage. Journal of Obstetrics and Gynaecology, 26, 335-338 doi:10.1080/01443610600595077

[12] Tattersall, M. and Braithwaite, W. (2007) Balloon tamponade for vaginal lacerations causing severe postpartum haemorrhage. British Journal of Obstetrics and Gynaecology, 114, 647-648.

doi:10.1111/j.1471-0528.2007.01278.x

[13] Condous, G.S., Arulkumaran, S., Symonds, I., Chapman, R., Sinha, A. and Razvi, K. (2003) The "tamponade test" in the management of massive postpartum hemorrhage. Obstetrics and Gynaecology, 101, 767-772. doi:10.1016/S0029-7844(03)00046-2

[14] Seror, J., Allouche, C. and Elhaik, S. (2005) Use of Sengstaken-Blakemore tube in massive postpartum hemorrhage: A series of 17 cases. Acta Obstetricia et Gynecologica Scandinavica, 84, 660-664.

[15] Treloar, E., Anderson, R., Andrews, H. and Bailey, J. (2006) Uterine necrosis following B-Lynch suture for primary postpartum haemorrhage. British Journal of Obstetrics and Gynaecology, 113, 486-488. doi:10.1111/j.1471-0528.2006.00890.x

[16] Lodhi, W., Golara, M., Karangaokar, V. and Yoong, W. (2012) Uterine necrosis following application of combined uterine compression suture with intrauterine balloon tamponade. Journal of Obstetrics and Gynaecology, 
32, 30-31. doi:10.3109/01443615.2011.614972

[17] Diemert, A., Ortmeyer, G., Hollwitz, B., Lotz, M., Somville, T., Glosemeyer, P., et al. (2012) The combination of intrauterine balloon tamponade and the B-Lynch procedure for the treatment of severe postpartum hemorrhage. American Journal of Obstetrics and Gynecology, 206, e1e4.

[18] Thapa, K., Malla, B., Pandey, S. and Amatya, S. (2010)
Intrauterine condom tamponade in management of post partum hemorrhage. Journal of Nepal Health Research Council, 8, 19-22

[19] Stavroulis, A., Memtsa, M., Aref-Adib, M., Fakokunde, A. and Yoong, W. (2009) Management of postpartum haemorrhage with Bakri balloon Tamponade. International Journal of Gynaecology and Obstetrics, 107, S348. 